\title{
The rules of temporal and spatial migration of Cd content
}

\author{
Dongfang Yang ${ }^{1,2, *}$, Hexin Jiang ${ }^{1}$, Longlei Zhang ${ }^{1}$, Qi Wang ${ }^{1}$, Haixia Li $^{1}$ \\ ${ }^{1}$ Accountancy School, Xijing University, Xi'an 710123, China \\ ${ }^{2}$ North China Sea Environmental Monitoring Center, SOA, Qingdao 266033, China
}

\begin{abstract}
According to the survey dataset on the waters of Jiaozhou Bay from 1984 to 1988, this paper discusses the data of $\mathrm{Cd}$ content each year. From the perspectives of content size, horizontal distribution, vertical distribution, seasonal distribution, regional distribution, structural distribution and tendency distribution, it studies the source, water quality, distribution and migration conditions of $\mathrm{Cd}$ content in the waters of Jiaozhou Bay. On the scale of space, 21 migration rules have been gotten during the spatial and temporal variation process of $\mathrm{Cd}$ content in the waters of Jiaozhou Bay.
\end{abstract}

\section{Introduction}

$\mathrm{Cd}$ is an indispensable important compound in our daily life. In the process of industrial and agricultural production and development, humans continuously emit $\mathrm{Cd}$ content to land, atmosphere and ocean [1 10]. Therefore, study on the spatial and temporal variation rules and process of $\mathrm{Cd}$ content in the waters has great significance on the research of $\mathrm{Cd}$ migration process.

Based on the survey materials about the waters of Jiaozhou Bay in the period from 1984 to 1988, this paper studies the existing conditions of $\mathrm{Cd}$ content in the waters of Jiaozhou Bay each year [1-10]. The research on the spatial and temporal variation rules of $\mathrm{Cd}$ content in the waters of Jiaozhou Bay will provide theoretical basis for understanding the environmental contamination through $\mathrm{Cd}$ content.

\section{Survey waters, materials and methods}

\subsection{The natural environment of Jiaozhou Bay.} Jiaozhou Bay is located in the southern part of Shandong Peninsula. Its geographical position is between $120^{\circ} 04^{\prime}-120^{\circ} 23^{\prime} \mathrm{E}$ and $35^{\circ} 58^{\prime}-36^{\circ} 18^{\prime} \mathrm{N}$. It is bounded by the line connecting Tuan Island and Xuejia Island, and is connected to the Yellow Sea. With an area of about $446 \mathrm{~km}^{2}$ and an average water depth of about $7 \mathrm{~m}$, it is a typical semi-enclosed bay (Figure 1) [11, 12].

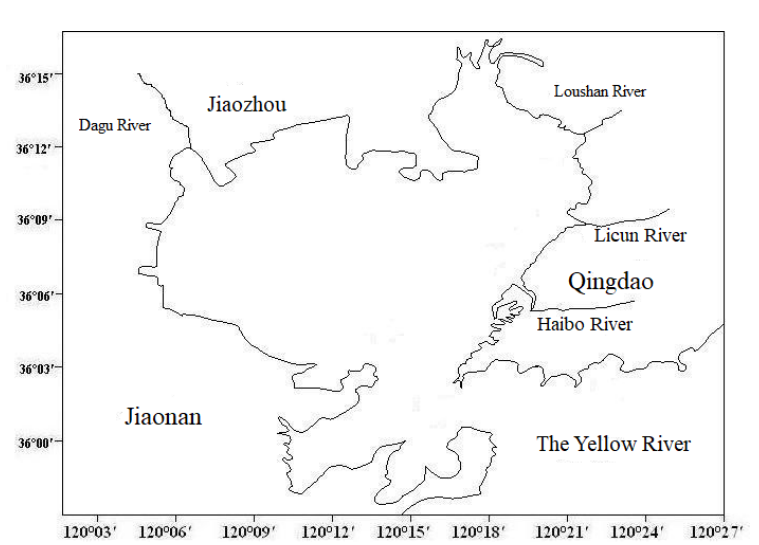

Fig.1 Geography location of Jiaozhou Bay

2.2 Data source and method. The survey data used in this study are provided by the North Sea Monitoring Center of the State Oceanic Administration. The survey of Cd content in Jiaozhou Bay water body [3-20] was carried out according to the national standard method, which was recorded in the national "Marine Monitoring Code" (1991) [13].

Conduct the survey of Cd content in the Jiaozhou Bay water body respectively in July, August, and October in 1984, April, July and October in 1985, April, July and October in 1986, May, July and November in 1987, and April, July and October in 1988 [3-10]. This study takes April, May, and June as spring, July, August, and September as summer, and October, November, and December as autumn.

\section{Results}

3.1 Study results in 1984. Based on the survey materials of Jiaozhou Bay water body in July, August and October in 1984, this paper studies the volume of $\mathrm{Cd}$ content and the surface horizontal distribution in the 
waters of Jiaozhou Bay. The results show that the content of $\mathrm{Cd}$ in Jiaozhou Bay water body ranges within $0.06-0.20 \mu \mathrm{g} / \mathrm{L}$, which meets the national water quality standards of Class I $(1.00 \mu \mathrm{g} / \mathrm{L})$. In the entire waters of Jiaozhou Bay, the water is clean and has not been polluted by $\mathrm{Cd}$ at all. $\mathrm{Cd}$ in the waters of Jiaozhou Bay only has one source, which is the transportation of offshore currents. The $\mathrm{Cd}$ content delivered is $0.17-0.20 \mu \mathrm{g} / \mathrm{L}$. But in the entire waters of Jiaozhou Bay, the $\mathrm{Cd}$ content ranges in $0.06-0.12 \mu \mathrm{g} / \mathrm{L}$. Therefore, Jiaozhou Bay and its surrounding rivers and ground are not polluted by $\mathrm{Cd}$ content. It is believed that human beings are very fortunate that the water is clean in this water area, in terms of $\mathrm{Cd}$ content, as it is rare to have such a clean water area.

According to the survey data in the water area of Jiaozhou Bay in 1984, this paper studies the current status and horizontal distribution of $\mathrm{Cd}$ content in the bottom waters of the mouth of Jiaozhou Bay. The results show that in July and October, in the bottom waters of the mouth of Jiaozhou Bay, the Cd content ranges from 0.05 to $0.18 \mu \mathrm{g} / \mathrm{L}$, which conforms to the national water quality standards of Class I. This reveals that under the effect of vertical water body, the Cd content is relatively low and the water is clean, which means there is no $\mathrm{Cd}$ pollution at all. In the mouth waters of Jiaozhou Bay, in July and October, the Cd content in the surface water body has different values, resulting in a high sedimentation rate of $\mathrm{Cd}$ content in different places. In July, the high sedimentation rate with high $\mathrm{Cd}$ content in the surface water body appears inside the bay mouth. In October, the high sedimentation rate with low Cd content in surface water appears outside the bay mouth. Therefore, after the effect of vertical water body, there are areas of high $\mathrm{Cd}$ content in different places in the bottom waters of the mouth of Jiaozhou Bay.

According to the survey data of Jiaozhou Bay water body in 1984, it studies the vertical distribution and seasonal changes of $\mathrm{Cd}$ in the surface and bottom waters of the mouth of Jiaozhou Bay, and determines the seasonal distribution, horizontal distribution trend, variation range, vertical change and vertical migration process of $\mathrm{Cd}$ content in the surface and bottom waters. The results show that in the waters of bay mouth, the seasonal changes of $\mathrm{Cd}$ content in the surface and bottom are consistent, and the seasonal changes of $\mathrm{Cd}$ content from low to high are from summer to autumn. Moreover, this seasonal change is determined by the strength of the equatorial Kuroshio current. In the waters of bay mouth, in July and October, the following rules are revealed: on the spatial scale, the horizontal distribution trend of $\mathrm{Cd}$ content are consistent in July and October; the horizontal distribution of $\mathrm{Cd}$ content in the surface is consistent with it in the bottom in October; the horizontal distribution in the surface and bottom layers present the spatial subsidence process of $\mathrm{Cd}$ content. In the variation scale, the variation ranges of $\mathrm{Cd}$ content in the surface and bottom are almost the same. In the vertical scale, no matter that the $\mathrm{Cd}$ content is high or low, it keeps similar in the surface and bottom waters. In the regional scale, the offshore ocean current transports a few or tiny amounts of $\mathrm{Cd}$ to Jiaozhou Bay, which presents the $\mathrm{Cd}$ content in the surface are more than that in the bottom. Therefore, the vertical distribution and seasonal changes present the effects of horizontal water body and vertical water body, and reveal the horizontal migration process and vertical subsidence process of $\mathrm{Cd}$ content.

3.2 Study results in 1985. Based on the survey materials of Jiaozhou Bay water body in April, July and October in 1985, this paper studies the volume of $\mathrm{Cd}$ content and the surface horizontal distribution in the waters of Jiaozhou Bay. The results show that the content of $\mathrm{Cd}$ in Jiaozhou Bay water body ranges within $0.03-0.44 \mu \mathrm{g} / \mathrm{L}$, which meets the national water quality standards of Class I $(1.00 \mu \mathrm{g} / \mathrm{L})$. In the entire waters of Jiaozhou Bay, the water is clean and has not been polluted by $\mathrm{Cd}$ at all. $\mathrm{Cd}$ in the waters of Jiaozhou Bay only has one source, which is the transportation of offshore currents. The $\mathrm{Cd}$ content delivered is $0.21-0.44 \mu \mathrm{g} / \mathrm{L}$. Therefore, Jiaozhou Bay and its surrounding rivers and ground are not polluted by $\mathrm{Cd}$ content. The horizontal distribution of Cd content in the waters indicates that through the ocean tide and current, the content of material becomes low and further displays its uniformity. The author proposes The Uniformity Rules of Substance in the Waters based on the horizontal distribution of substance content, such as organics, heavy metals, etc.

According to the survey data in the water area of Jiaozhou Bay in 1985, this paper studies the current status and horizontal distribution of $\mathrm{Cd}$ content in the bottom waters of the mouth of Jiaozhou Bay. The results show that in April, July and October, in the bottom waters of the mouth of Jiaozhou Bay, the $\mathrm{Cd}$ content ranges from 0.04 to $0.32 \mu \mathrm{g} / \mathrm{L}$, which conforms to the national water quality standards of Class I. This reveals that under the effect of vertical water body, the $\mathrm{Cd}$ content is relatively low and the water is clean, which means there is no Cd pollution at all. In the mouth waters of Jiaozhou Bay, in April, July and October, the Cd content in the surface water body has different values, resulting in a high sedimentation rate of $\mathrm{Cd}$ content in different places. In April and October, the high sedimentation rate with high $\mathrm{Cd}$ content in the surface water body appears outside the bay mouth. In July, the high sedimentation rate with high $\mathrm{Cd}$ content in surface water appears in the bay mouth. Therefore, after the effect of vertical water body, there are areas of high $\mathrm{Cd}$ content in different places in the bottom waters of the mouth of Jiaozhou Bay. The author hereto proposes the Cd content subsidence mechanism.

According to the survey data of Jiaozhou Bay water body in 1985, it studies the vertical distribution and seasonal changes of $\mathrm{Cd}$ in the surface and bottom waters of the mouth of Jiaozhou Bay, and determines the seasonal distribution, horizontal distribution trend, variation range, vertical change and vertical migration process of $\mathrm{Cd}$ content in the surface and bottom waters. The results show that in the waters of bay mouth, the seasonal changes of $\mathrm{Cd}$ content in the surface and bottom 
are consistent, and the seasonal changes of $\mathrm{Cd}$ content from low to high are from summer to autumn then to spring. In the waters of bay mouth, in April, July and October, the following rules are revealed: on the spatial scale, the horizontal distribution trend of $\mathrm{Cd}$ content are consistent in the surface and bottom layers; on the variation scale, the variation ranges of $\mathrm{Cd}$ content in the surface and bottom are almost the same, where the variation range of $\mathrm{Cd}$ content in the surface is larger than it in the bottom. Low Cd content in the surface reaches seabed and gets accumulated while high $\mathrm{Cd}$ content in the surface reaches seabed and gets diluted. On the vertical scale, no matter that the Cd content is high or low, it keeps similar in the surface and bottom waters. On the regional scale, the river transports $\mathrm{Cd}$ content to Jiaozhou Bay, which presents the vertical changes of $\mathrm{Cd}$ content in the surface and bottom layers. For this, the author proposes the subsidence process of $\mathrm{Cd}$ content which reveals that in the spatial variation, the $\mathrm{Cd}$ content on the seabed is gradually increasing with continuous subsidence inside, outside and within the bay mouth. In addition, the author further proposes the vertical distribution process of $\mathrm{Cd}$ content in the surface and bottom layers, which reveals the variation ranges of $\mathrm{Cd}$ content in the surface and bottom layers are expanding as time goes on. However, it starts to repeat the process in the next year.

3.3 Study results in 1986. Based on the survey materials of Jiaozhou Bay water body in April, July and October in 1986, this paper studies the volume of $\mathrm{Cd}$ content and the surface horizontal distribution in the waters of Jiaozhou Bay. The results show that the content of $\mathrm{Cd}$ in the entire water body and the water in the bay mouth is very low, ranging within $0.01-0.94 \mu \mathrm{g} / \mathrm{L}$, which is lower than the national water quality standards of Class I, $1.00 \mu \mathrm{g} / \mathrm{L}$. But in the waters outside Jiaozhou Bay, the variation range of $\mathrm{Cd}$ content is $0.38 \sim 6.48 \mu \mathrm{g} / \mathrm{L}$ which conforms the national water quality standards of Class I, II and III. In the entire waters inside Jiaozhou Bay and the waters in the bay mouth, the water is clean and has not been polluted by $\mathrm{Cd}$ at all. But the waters outside the bay is moderate contaminated by $\mathrm{Cd}$. Cd in the waters of Jiaozhou Bay only has two sources, the transportation of river and offshore currents. The $\mathrm{Cd}$ content delivered by river is $0.75-0.44 \mu \mathrm{g} / \mathrm{L}$ and $6.48 \mu \mathrm{g} / \mathrm{L}$ delivered by offshore currents. Therefore, Jiaozhou Bay and its surrounding rivers and ground are not polluted by $\mathrm{Cd}$ content while the offshore seawaters have gotten moderate contamination.

According to the survey data in the water area of Jiaozhou Bay in April, July and October of 1986, this paper studies the volume variation and horizontal distribution of $\mathrm{Cd}$ content. The results indicate that the $\mathrm{Cd}$ content in the waters varies within $0.01-0.94 \mu \mathrm{g} / \mathrm{L}$ on the spatial scale of entire water area of Jiaozhou Bay and the water area in the bay mouth and on the temporal scale from April to October. It demonstrates that $\mathrm{Cd}$ content keeps uniformity in waters as time and space change, and reveals that the ocean, under the effects of tide and ocean currents, has the characteristic of uniformity as well. Therefore, the spatial and temporal variation of $\mathrm{Cd}$ content in the waters demonstrate the uniformity theory proposed by the author. Moreover, the gulf has the characteristic of material homogeneity. When there is material transported to the gulf, the gulf will become inhomogeneity. It is the transportation source that delivers inhomogeneity.

According to the survey data in the water area of Jiaozhou Bay in 1986, this paper studies the current status and horizontal distribution of $\mathrm{Cd}$ content in the bottom waters of the mouth of Jiaozhou Bay. The results show that in April and July, in the bottom waters of the mouth of Jiaozhou Bay, the Cd content ranges from 0.00 to $1.29 \mu \mathrm{g} / \mathrm{L}$, which conforms to the national water quality standards of Class I and II. This reveals that under the effect of vertical water body, the water in the bottom of Jiaozhou Bay is slightly contaminated by $\mathrm{Cd}$. In the outside waters of the bay mouth, in April and July, the $\mathrm{Cd}$ content has a high sedimentation rate. Therefore, the $\mathrm{Cd}$ content in the surface layer reaches relatively high value and after the effect of vertical water body, the $\mathrm{Cd}$ content in the bottom also reaches a relatively high value. The author hereto proposes the $\mathrm{Cd}$ content subsidence process: In different periods, the content of $\mathrm{Cd}$ has high sedimentation rate in the waters outside the bay mouth.

According to the survey data of Jiaozhou Bay water body in 1986, it studies the vertical distribution and seasonal changes of $\mathrm{Cd}$ in the surface and bottom waters of the mouth of Jiaozhou Bay, and determines the seasonal distribution, horizontal distribution trend, variation range, vertical change and vertical migration process of Cd content in the surface and bottom waters. The results show that in the waters of bay mouth, the seasonal changes of $\mathrm{Cd}$ content in the surface and bottom are consistent, and the seasonal changes of $\mathrm{Cd}$ content from low to high are from spring to summer. In the waters of bay mouth, in April and October, the following rules are revealed: on the spatial scale, the horizontal distribution trend of $\mathrm{Cd}$ content are consistent in the surface and bottom layers; on the variation scale, the variation ranges of $\mathrm{Cd}$ content in the surface and bottom are almost the same, where the variation range of $\mathrm{Cd}$ content in the surface is larger than it in the bottom. Low $\mathrm{Cd}$ content in the surface reaches seabed and gets accumulated while high $\mathrm{Cd}$ content in the surface reaches seabed and gets diluted. On the vertical scale, no matter that the $\mathrm{Cd}$ content is high or low, it keeps similar in the surface and bottom waters. On the regional scale, the offshore current transports $\mathrm{Cd}$ content to Jiaozhou Bay, which presents the vertical changes of $\mathrm{Cd}$ content in the surface and bottom layers. For this, the author proposes the subsidence process of $\mathrm{Cd}$ content which reveals that in the spatial and temporal variation, the $\mathrm{Cd}$ content on the seabed is gradually increasing with continuous subsidence inside, outside and within the bay mouth. In addition, the author further proposes the vertical distribution process of $\mathrm{Cd}$ content in the surface and bottom layers, which reveals the variation ranges of $\mathrm{Cd}$ content in the surface and bottom layers are expanding as time goes on. However, it starts to repeat the process in the next year. 
3.4 Study results in 1987. Based on the survey materials of Jiaozhou Bay water body in May, July and November in 1987, this paper studies the volume of $\mathrm{Cd}$ content and the surface horizontal distribution in the waters of Jiaozhou Bay. The results show that the content of $\mathrm{Cd}$ in the entire Jiaozhou Bay water body is very low, ranging within $0.07-0.68 \mu \mathrm{g} / \mathrm{L}$, which meets the national water quality standards of Class I $(1.00 \mu \mathrm{g} / \mathrm{L})$. In May, July and October and in the entire waters of Jiaozhou Bay, the water is clean and has not been polluted by $\mathrm{Cd}$ at all. $\mathrm{Cd}$ in the waters of Jiaozhou Bay only has one source, which is the transportation of rivers. The $\mathrm{Cd}$ content delivered by rivers is $0.12-0.68 \mu \mathrm{g} / \mathrm{L}$. Therefore, the $\mathrm{Cd}$ content delivered by rivers in land conforms the national water quality standards of Class I, $1.00 \mu \mathrm{g} / \mathrm{L}$, indicating that the rivers have not been polluted by $\mathrm{Cd}$ and the water quality is great.

3.5 Study results in 1988. Based on the survey materials of Jiaozhou Bay water body in April, July and October in 1988, the variation of Cd content in the waters

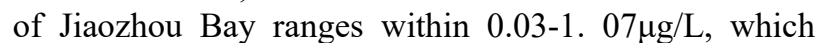
conforms to the national water quality standards of Class I and II. It indicates that the entire water of Jiaozhou Bay has been slightly polluted by $\mathrm{Cd}$ in April, July and October. The Cd content in the waters of Jiaozhou Bay has three sources, the transportation of rivers, offshore currents and atmospheric sedimentation. The $\mathrm{Cd}$ content delivered by rivers is $1.07 \mu \mathrm{g} / \mathrm{L}$, by offshore currents is $0.12 \mu \mathrm{g} / \mathrm{L}$ and by atmospheric sedimentation is $0.04 \mu \mathrm{g} / \mathrm{L}$. They present that rivers do get slightly polluted by $\mathrm{Cd}$ while the offshore currents and atmospheric sedimentation do not get polluted at all. The $\mathrm{Cd}$ content in the waters of Jiaozhou Bay passes through three channels, land, ocean and atmosphere, and the $\mathrm{Cd}$ content transported by each channel differs by an order of magnitude. The author builds a model to present the migration channels of $\mathrm{Cd}$ content and quantitatively reveals the migration process that $\mathrm{Cd}$ content migrates to land, ocean and atmosphere through human emissions.

According to the survey data in the water area of Jiaozhou Bay in 1988, this paper studies the current status and horizontal distribution of $\mathrm{Cd}$ content in the bottom waters of the mouth of Jiaozhou Bay. The results show that in April and July, the Cd content in the waters of Jiaozhou Bay ranges from 0.024 to $0.128 \mu \mathrm{g} / \mathrm{L}$, which conforms to the national water quality standards of Class I. This reveals that the bottom waters in the mouth of Jiaozhou Bay do not get polluted by Cd content in April and July. Under the effect of vertical water body, it appears high sedimentation rate of Cd content in the bay mouth and central waters in April, and in the inner waters of the bay in July. The author proposes the subsidence characteristics of Cd content: Under different sources, the $\mathrm{Cd}$ content will subside to the path along the transportation direction through the transportation of tide and ebb. Therefore, it appears the high $\mathrm{Cd}$ content sedimentation on this path. Thus the high sedimentation area of $\mathrm{Cd}$ content in the surface is driven by the current when it subsides to the seabed.
According to the survey data of Jiaozhou Bay water body in 1988, it studies the vertical distribution and seasonal changes of $\mathrm{Cd}$ in the surface and bottom waters of the mouth of Jiaozhou Bay, and determines the seasonal distribution, variation range and water effect of $\mathrm{Cd}$ content in the surface and bottom waters. The results show that in the waters of bay mouth, the seasonal changes of $\mathrm{Cd}$ content in the surface from low to high is from spring to summer. Under the vertical water body effect, the $\mathrm{Cd}$ content in the bottom waters from low to high is from spring to summer. So, from April to July, the $\mathrm{Cd}$ content in the surface subsides to the seabed that presents seasonal changes of Cd content in the surface, which varies based on the transportation sources of offshore currents and rivers. But the seasonal changes of $\mathrm{Cd}$ content in the bottom varies according to the dilution effect of vertical water body. In the waters of bay mouth, in April and July, the following rules are revealed: in the vertical distribution, when the $\mathrm{Cd}$ content in the surface is relatively low, the $\mathrm{Cd}$ content in the corresponding bottom is low; when the $\mathrm{Cd}$ content in the surface is relatively high, the $\mathrm{Cd}$ content in the corresponding bottom is high. On the variation scale, the variation ranges of $\mathrm{Cd}$ content in the surface and bottom are almost the same. As $\mathrm{Cd}$ subsides to the seabed rapidly and continuously, the variation of $\mathrm{Cd}$ content in the surface and bottom keeps uniformity. On the scale of water body effect, the variation of $\mathrm{Cd}$ content in the surface and bottom reveals the dilution effect of vertical water body: low $\mathrm{Cd}$ content arrives seabed and gets diluted, and high $\mathrm{Cd}$ content arrives seabed and gets diluted as well. Therefore, the variation range of $0.09-0.45 \mu \mathrm{g} / \mathrm{L}$ for the $\mathrm{Cd}$ content in the surface is larger than that of $0.08-0.18 \mu \mathrm{g} / \mathrm{L}$ in the bottom. The low value of $\mathrm{Cd}$ content in the surface is larger than that in the bottom, and the high value in the surface is larger than that in the bottom as well.

According to the survey data of Jiaozhou Bay water body in 1988, this paper studies the vertical changes of $\mathrm{Cd}$ content in the surface and bottom waters of Jiaozhou Bay, and determines the spatial and temporal variation changes of subsidence process of $\mathrm{Cd}$ content. The results show that the $\mathrm{Cd}$ content in the surface waters outside bay mouth is more than that in the bottom while the $\mathrm{Cd}$ content in the surface waters in the bay mouth is less than that in the bottom, in April. In addition, in the central waters of the bay, the $\mathrm{Cd}$ content in the surface and bottom is the same. In July, in the waters nearby rivers estuary, the $\mathrm{Cd}$ content in the surface is larger than that in the bottom in the waters inside the bay and central waters. In the southwestern water area, the $\mathrm{Cd}$ content in the surface is less than that in the bottom. On the temporal scale, the $\mathrm{Cd}$ content has three statuses during the subsidence process: 1) When the Cd content transported from the sources has not been sedimented to the seabed, the $\mathrm{Cd}$ content in the bottom is relatively low and it presents that the $\mathrm{Cd}$ content in the surface is more than that in the bottom. 2) When the sources supply a large amount of $\mathrm{Cd}$ content, it will accumulate on the seabed after longtime sedimentation, resulting that the $\mathrm{Cd}$ content in the bottom is more than that in the surface. 3) When the sources supply Cd content but the waters are 
not affected by the $\mathrm{Cd}$ content, it will present a uniform mixing status in the surface and bottom layers. On the spatial scale, there are also three statuses of $\mathrm{Cd}$ content in the process of sedimentation: 1) When the sources provide $\mathrm{Cd}$ content, it presents the $\mathrm{Cd}$ content in the surface is more than that in the bottom in the waters nearby sources. 2) When the sources transport Cd content and pass through a length of path, the Cd content in the waters far away from the sources and in the transportation path will present a higher content in the surface than it in the bottom. 3) When the sources transport $\mathrm{Cd}$ content, in waters far away from the source and not affected by the Cd content, the Cd content of the surface and bottom layers are mixed evenly. In the waters of Jiaozhou Bay, according to the temporal and spatial variation of $\mathrm{Cd}$ content sedimentation process, the author proposes the temporal and spatial variation of $\mathrm{Cd}$ content sedimentation rules: the change of $\mathrm{Cd}$ content in the surface and bottom layers is determined by the content of the source and the migration distance. Therefore, the change of $\mathrm{Cd}$ content in the surface and bottom layer reveals the water migration process of $\mathrm{Cd}$ content.

According to the survey data of Jiaozhou Bay in April, July and October 1988, it studies the surface horizontal distribution of $\mathrm{Cd}$ content in Jiaozhou Bay waters. The author proposes the definition, model and classification standard of Yang Dongfang water material content uniform. The Yang Dongfang water material content uniform is defined as the degree of difference between high and low water material content. Yang Dongfang also proposes the two concepts of non-uniform column of water material content and uniformity of water material content. These two concepts are used to describe the uniformity of water material content. At the same time, the author proposes a model of water material content uniform, which is composed of a non-uniform column model of water material content and a uniformity model of water material content. The uniform model of water material content is described as follows: 1 . the variation range of material content; 2 . the uniformity of material content in the water body. The author further proposes the classification standard of Yang Dongfang material content uniformity, which is divided into six parts with the description of uniformity: the most non-uniform, non-uniform, low-level uniform, significantly uniform, highly uniform, and most uniform. According to the definition, model, and classification standard of Yang Dongfang water material content uniform, it is calculated: In the waters of Jiaozhou Bay, in April, the non-uniform column of $\mathrm{Cd}$ content is: $0.01 \mu \mathrm{g} / \mathrm{L}$, and the uniformity of Cd content is $90 \%$, so the uniformity of $\mathrm{Cd}$ content is significantly uniform. In July, the non-uniform column of $\mathrm{Cd}$ content is $0.97 \mu \mathrm{g} / \mathrm{L}$, and the uniformity of $\mathrm{Cd}$ content is $9 \%$, so the uniformity of $\mathrm{Cd}$ content is non-uniform. In October, the non-uniform column of the $\mathrm{Cd}$ content is $0.01 \mu \mathrm{g} / \mathrm{L}$, and the uniformity of $\mathrm{Cd}$ content is $75 \%$, so the uniformity of the $\mathrm{Cd}$ content is significantly uniform. According to the definition, model and classification standard of Yang Dongfang water material content uniform, it fully quantifies the change process of material content in time and space.

\section{Discussion}

4.1 Content fluctuates and increases year by year. According to the survey data of Jiaozhou Bay waters from 1984 to 1988 , the volume of $\mathrm{Cd}$ content and variations in years and seasons in the waters of Jiaozhou Bay are studied here. The results show that during the period from 1984 to 1988 , the change of Cd content has seasonal changes. Compared with spring, summer and autumn, the Cd content in the wates of Jiaozhou Bay is relatively high in spring, high in summer, and low in autumn. From 1984 to 1988, in spring and autumn, Jiaozhou Bay is kept free from any pollution of $\mathrm{Cd}$ content; but in summer, Jiaozhou Bay is sometimes polluted with light or moderate Cd content. During the period from 1984 to 1988 , the change of the Cd content in the Jiaozhou Bay waters shows that the entire water of Jiaozhou Bay is very clean in terms of $\mathrm{Cd}$ content in the first two years. During the third year, the $\mathrm{Cd}$ content in the Jiaozhou Bay water begins to be affected by the transportation of human activities, and a large amount of $\mathrm{Cd}$ content is imported into the Jiaozhou Bay waters, causing the Jiaozhou Bay water to be slightly and moderately polluted. In the fourth year, in terms of $\mathrm{Cd}$ content, the entire Jiaozhou Bay water body has recovered to be very clean. In the fifth year, the $\mathrm{Cd}$ content in the Jiaozhou Bay water body is transported by human activities, causing the Jiaozhou Bay water body to be slightly polluted by the $\mathrm{Cd}$ content. Therefore, during the period from 1984 to 1988 , the amount of $\mathrm{Cd}$ discharged to Jiaozhou Bay increases in the water body of Jiaozhou Bay, but the entire waters of Jiaozhou Bay can accommodate the input of $\mathrm{Cd}$ content. After the self-purification process of the Jiaozhou Bay water body, in terms of $\mathrm{Cd}$ content, a very clean water body is maintained.

\subsection{Sources' variation in time and space.}

According to the survey data of Jiaozhou Bay waters from 1984 to 1988, it analyzes the horizontal distribution of $\mathrm{Cd}$ content in the waters of Jiaozhou Bay and its sources variation, and determines the location, scope and change process of the source of $\mathrm{Cd}$ content. The results of the study show that during the period from 1984 to 1988, the Cd content in the Jiaozhou Bay waters has three sources, mainly from the transportation of $0.12 \sim 6.48 \mu \mathrm{g} / \mathrm{L}$ by ocean currents in the open sea, the transportation of $0.12 \sim 1.07 \mu \mathrm{g} / \mathrm{L}$ by rivers and the transportation of $0.04 \mu \mathrm{g} / \mathrm{L}$ by atmospheric subsidence. These three ways bring $\mathrm{Cd}$ content to the entire waters of Jiaozhou Bay, and the $\mathrm{Cd}$ content varies from 0.04 to $6.48 \mu \mathrm{g} / \mathrm{L}$. During the period from 1984 to 1988 , the $\mathrm{Cd}$ content transported by the offshore ocean currents is sometimes low and sometimes high. The $\mathrm{Cd}$ content transported by the river is from zero, to relatively low, and then to a relatively high $\mathrm{Cd}$ content. The $\mathrm{Cd}$ content transported by atmospheric subsidence keeps zero at the beginning until it finally appears. The $\mathrm{Cd}$ content produced by human activities is constantly increasing, which is continuously affecting the environment and the 
way to transport Cd content.

\subsection{The ratio of the highest content of $\mathrm{Cd}$ to the highest capacity in the water body. According to} the survey data of Jiaozhou Bay waters from 1984 to 1988 , it analyzes the seasonal changes and source changes of $\mathrm{Cd}$ content in Jiaozhou Bay waters. The results of the study show that during the seasonal changes in spring, summer, and autumn, the $\mathrm{Cd}$ content in the water body depends on the input of the source of $\mathrm{Cd}$ content. There are three sources of $\mathrm{Cd}$ content in the waters of Jiaozhou Bay, mainly from the transportation of $0.12 \sim 6.48 \mu \mathrm{g} / \mathrm{L}$ by ocean currents in the open sea, the transportation of $0.12 \sim 1.07 \mu \mathrm{g} / \mathrm{L}$ by rivers and the transportation of $0.04 \mu \mathrm{g} / \mathrm{L}$ by atmospheric subsidence. During the period from 1984 to 1988, with the increase of human activities, the $\mathrm{Cd}$ content in the ocean is relatively high; the $\mathrm{Cd}$ content transported by rivers grows from nothing and then from low to high, showing an increasing trend; the atmosphere also appears $\mathrm{Cd}$ content. The highest content transported by ocean currents in the open sea accounts for $85.37 \%$ of the three transport sources, the highest content transported by rivers accounts for $14.09 \%$ of the three transport sources, and the highest content transported by atmospheric subsidence accounts for $0.52 \%$ of the three transport sources. The maximum capacity of ocean current transportation in the open sea accounts for $60.03 \%$ of the three sources of transportation, the maximum capacity of river transportation accounts for $39.62 \%$ of the three sources of transportation, and the capacity of atmospheric subsidence transportation accounts for $0.34 \%$ of the three transportation sources. Therefore, the maximum capacity of $\mathrm{Cd}$ in a water body is mainly determined by the $\mathrm{Cd}$ content transported by ocean currents in the open sea.

\subsection{Subsidence process and characteristics.} According to the survey data of Jiaozhou Bay waters from 1984 to 1988, the changes of $\mathrm{Cd}$ content in the bottom layer and its distribution are analyzed. The results show that in the bottom water body of Jiaozhou Bay, the distribution in the bottom layer has the following characteristics: During the period of 1979 to 1983, from April to November, the bottom $\mathrm{Cd}$ content in the water body of Jiaozhou Bay varies from 0.00 to $1.29 \mu \mathrm{g} / \mathrm{L}$, in line with national water quality standards of Class I and II. This shows that in terms of Cd content, from April to November except for July 1986, the water in the bottom of Jiaozhou Bay is clean and is not polluted by $\mathrm{Cd}$ at all. Then, only in July 1986, in the bottom waters of Jiaozhou Bay, the water is slightly polluted by $\mathrm{Cd}$ content. This shows that in the bottom waters of Jiaozhou Bay, the degree and time of pollution of $\mathrm{Cd}$ content are very short. From 1984 to 1988, in the bottom waters of Jiaozhou Bay, in April, the $\mathrm{Cd}$ content gradually decreased over time from 1985 to 1988. In July, from 1984 to 1988 , as time changes, the Cd content increases substantially. In the bottom waters of Jiaozhou Bay, the seasonal changes of $\mathrm{Cd}$ content in the bottom water from low to high are: autumn, spring, and summer. This shows that in the bottom waters of Jiaozhou Bay, the Cd content forms a parabolic change with the seasonal changes of the year. From 1984 to 1988, the river transportation and ocean current transportation of $\mathrm{Cd}$ content to Jiaozhou Bay show that the $\mathrm{Cd}$ content is rapidly sinking and accumulated in the bottom layer. The $\mathrm{Cd}$ content transported by the river can sink to the bottom waters inside the bay mouth, bay mouth and outside the bay mouth. The Cd content transported by ocean currents in the open sea can sink to the bottom waters inside and outside the bay mouth. During this five-year period, the river transportation is four years, and the offshore ocean current transportation is five years. When the Cd content transported by the offshore ocean currents is relatively high, the high subsidence area appears in the bottom waters outside the bay mouth. When the $\mathrm{Cd}$ content conveyed by the river is relatively high, the high subsidence area appears in the bottom water area inside the bay mouth.

\subsection{Yang Dongfang horizontal distribution trend} process. Based on the survey data of Jiaozhou Bay waters from 1984 to 1986, the author studies the horizontal distribution trend of $\mathrm{Cd}$ content in the surface and bottom layer, and proposes the Yang Dongfang horizontal distribution trend process. This process has three forms: 1) Yang Dongfang horizontal distribution trend process I: Cd content subsidence does not reach the seabed. The horizontal distribution trend of $\mathrm{Cd}$ content in the surface layer is decreasing, while the horizontal distribution trend of the bottom layer remains unchanged. 2) Yang Dongfang horizontal distribution trend process II: Cd content has rapidly subsided and reached the seabed. The horizontal distribution trend of $\mathrm{Cd}$ content in the surface layer is consistent with that of the bottom layer. 3) Yang Dongfang horizontal distribution trend process III. The sedimentation of $\mathrm{Cd}$ content not only reaches the seabed, but also accumulates on the seabed. The horizontal distribution trend of $\mathrm{Cd}$ content in the surface layer remains unchanged, while the horizontal distribution trend of the bottom layer is increasing. The author proposes the Yang Dongfang horizontal distribution trend process, which shows the waters migration trend process of $\mathrm{Cd}$ content and fully demonstrates the temporal and spatial change of $\mathrm{Cd}$ content migration trend. It strongly determines the correlation between the changing trend of $\mathrm{Cd}$ content in the surface layer, the changing trend of $\mathrm{Cd}$ content in the bottom layer, and the changing trend of $\mathrm{Cd}$ content in the surface and bottom layer during the change of time and space. In addition, the author proposes a block diagram of the waters migration trend process model of $\mathrm{Cd}$ content, explains the path and trajectory left by the $\mathrm{Cd}$ content, and predicts the horizontal distribution trend of $\mathrm{Cd}$ content in the surface and bottom waters.

4.6 Yang Dongfang water clearance. Based on the survey data of Jiaozhou Bay waters from 1984 to 1988 (lack of the data in 1987), it studies the changes of $\mathrm{Cd}$ content in the surface and bottom of Jiaozhou Bay waters and the vertical distribution. The results show that during 
the period from 1984 to 1988 (lack of 1987), the difference in the variation range of the surface and bottom $\mathrm{Cd}$ content in the Jiaozhou Bay water body does not exceed 0.01 to $6.48 \mu \mathrm{g} / \mathrm{L}$ in the positive and negative values, which indicates that the changes of $\mathrm{Cd}$ content in the surface and bottom layers are basically the same. And the surface layer with high $\mathrm{Cd}$ content corresponds to the high content of bottom layer; similarly, when the surface layer with $\mathrm{Cd}$ content is low, the corresponding bottom layer is low. This shows that the Cd content subsidence is rapid, maintaining the consistency of the content in the surface and bottom layer. Especially when there is no source of $\mathrm{Cd}$ content, the $\mathrm{Cd}$ content in the surface and bottom waters of Jiaozhou Bay is very uniform, with a difference of $0.01 \mu \mathrm{g} / \mathrm{L}$. The author proposes the absolute sedimentation amount, relative sedimentation amount, absolute accumulation amount, and relative accumulation amount of $\mathrm{Cd}$ content. And it can be calculated that the absolute sedimentation volume of $\mathrm{Cd}$ content is $0.14-6.47 \mu \mathrm{g} / \mathrm{L}$, the relative sedimentation volume of $\mathrm{Cd}$ content is $70.0 \%-99.8 \%$; the absolute accumulation volume of $\mathrm{Cd}$ content is $0.10-1.29 \mu \mathrm{g} / \mathrm{L}$, the relative accumulation volume of $\mathrm{Cd}$ content is $55.5 \%-100.0 \%$. The calculation results show that when the Cd content of the surface layer is high, the sedimentation amount is large; when the $\mathrm{Cd}$ content of the surface layer is low, the sedimentation amount is small. The $\mathrm{Cd}$ content of the surface and the bottom layer is always consistent. In this way, the sedimentation amount is consistent to the level of the content. The calculation results further show that the $\mathrm{Cd}$ content of the bottom layer is high, and the relative accumulation amount corresponding to the $\mathrm{Cd}$ content of the bottom layer is high; similarly, the $\mathrm{Cd}$ content of the bottom layer is low, and the relative accumulation amount corresponding to the $\mathrm{Cd}$ content of the bottom layer is low. The author proposes the Yang Dongfang water clearance and uses mathematical expressions to describe them, revealing the migration process of substances in the waters. The author also proposes the spatiotemporal change state of $\mathrm{Cd}$ content in the vertical migration process, and establishes a plane model block diagram, which fully shows that the vertical migration process occurs in practice has nine states in total. At the same time, the author reveals the characteristics of vertical variation in the surface and bottom layers in the vertical migration process of $\mathrm{Cd}$ content in waters.

4.7 Rules of spatial migration process. According to the survey and analysis of the $\mathrm{Cd}$ content in the waters of Jiaozhou Bay from 1984 to 1988 [3 10], it has shown that the annual study results have the following rules:

(1) The Cd content in the waters of Jiaozhou Bay mainly comes from the transportation of ocean currents and rivers.

(2) In a year, the Cd content in the water body has experienced a process of changing from uneven to uniform.

(3) The Cd content produced by human activities has a great impact on rivers.
(4) As time changes, the $\mathrm{Cd}$ content in the environmental field is continuously increasing.

(5) The variation range of $\mathrm{Cd}$ content in the surface and bottom layer is basically the same, and the changes of $\mathrm{Cd}$ content in the surface and bottom layer maintain consistency.

(6) The Cd content in the surface and bottom layer remains similar, and it is consistent in the surface and bottom layer.

(7) In the process of spatiotemporal changes, the $\mathrm{Cd}$ content transported by the sources pass through the water body from the surface layer to the bottom layer.

(8) The source of $\mathrm{Cd}$ content and the special topography determine the high subsidence area of $\mathrm{Cd}$ content.

(9) The Cd content in the surface water body is continuously decreasing as far away from the source. Similarly, the Cd content in the surface water body is continuously decreasing as the content in the source decreases.

(10) The seasonal variation of Cd content in the water of Jiaozhou Bay is determined by the process of land migration, atmospheric migration, and ocean current migration.

(11) The Cd content of rivers is determined by the presence of human activities, the $\mathrm{Cd}$ content of the atmosphere is also determined by the presence of nature, and the $\mathrm{Cd}$ content of the ocean is determined by the presence of nature and human activities.

(12) With the change of time, the transported $\mathrm{Cd}$ content is gradually increasing, and the source of transported Cd content is gradually increasing. The high subsidence area that leaves in the seabed with $\mathrm{Cd}$ content is gradually increasing, and the $\mathrm{Cd}$ content in the high subsidence area is gradually increasing.

(13) The Cd content has rapid sedimentation, and the sedimentation amount is consistent with the content.

(14) The Cd content has undergone continuous subsidence and has a cumulative effect on the seabed

(15) The Cd content shows the repeated cycle of appearing, disappearing, appearing and disappearing.

(16) In the change from the Cd content in the surface layer to the end of the subsidence, the $\mathrm{Cd}$ content has rapid subsidence, and it also has the accumulation on the seabed. In addition, the $\mathrm{Cd}$ content can disappear in the surface layer as well as the bottom layer.

(17) As time changes, the relative sedimentation amount and relative accumulation amount of $\mathrm{Cd}$ content are very stable and very high.

(18) The sedimentation of $\mathrm{Cd}$ content is rapid and thorough, with the characteristics of easy sedimentation and volatile.

(19) The accumulation of $\mathrm{Cd}$ content is stable and complete, with the characteristics of easy accumulation and easy sedimentation.

(20) The change of $\mathrm{Cd}$ content in the surface and bottom layer is determined by the level of $\mathrm{Cd}$ content from the estuary and the distance of its migration.

(21) If the source stops providing $\mathrm{Cd}$ content, the $\mathrm{Cd}$ content in the entire water body will disappear without a trace.

Therefore, the study results above have revealed the 
migration rules of $\mathrm{Cd}$ content in the waters as space changes.

\section{Conclusion}

According to the survey data of waters in Jiaozhou Bay from 1984 to 1988, this paper studies the source, water quality, distribution and migration of $\mathrm{Cd}$ content in the waters of Jiaozhou Bay and gets many migration rules and results, from the perspective of content size, horizontal distribution, vertical distribution, seasonal distribution, regional distribution, structural distribution and trend distribution, through the annual data analysis on the spatial scale.

According to the survey data of Jiaozhou Bay waters from 1984 to 1988, on the time scale, through five-year $\mathrm{Cd}$ content data exploration, the changing process of $\mathrm{Cd}$ content in Jiaozhou Bay waters is studied, and the following research results can be obtained: 1. Content fluctuates and increases year by year; 2. Spatiotemporal variation of sources; 3 . The ratio of the highest content of $\mathrm{Cd}$ to the highest capacity in the water body; 4 . Subsidence process and characteristics; 5. Yang Dongfang horizontal distribution trend process; 6 . Waters vertical migration process - Yang Dongfang water clearance. It presents the dynamic migration process and variation trend of $\mathrm{Cd}$ content in the waters of Jiaozhou Bay over time.

In the process of human activities such as mine development, industrial waste discharge and domestic sewage discharge, humans continuously discharge $\mathrm{Cd}$ content to land, atmosphere and sea. Through land, atmosphere and ocean transportation, the $\mathrm{Cd}$ content is finally transported to the ocean, such as Jiaozhou Bay. These sources determine the changing process of $\mathrm{Cd}$ content in the water body of Jiaozhou Bay.

\section{References}

1. Dongfang Yang, Zhenqing Miao. Marine Bay Ecology (Volume 1) [M]. Beijing: China Ocean Press, 2010, 1-320.

2. Dongfang Yang, Zhenhui Gao. Marine Bay Ecology (Volume 2) [M]. Beijing: China Ocean Press, 2010, 1-330.

3. Dongfang Yang, Fengyou Wang, Sixi Zhu, Ming Wang, Xiuqin Yang. Homogeneity of $\mathrm{Cd}$ contents in Jiaozhou Bay waters [J]. Advances in Engineering Research. 2016, Vol.65: 298-302.

4. Dongfang Yang, Xiancheng Qu,Yu Chen, Shubo Fang and Yinjiang Zhang. Sedimentation mechanism of $\mathrm{Cd}$ in Jiaozhou Bay waters [J]. Advances in Engineering Research. 2016, 80: 993-997.

5. Dongfang Yang, Danfeng Yang, Sixi Zhu, Zhikang Wang, Ming Wang. Sedimentation process and vertical distribution of $\mathrm{Cd}$ in Jiaozhou Bay [J]. Advances in Engineering Research. 2016, 80: 998-1002.

6. Dongfang Yang, Sixi Zhu, Zhikang Wang, Xiuqin
Yang, Fengyou Wang. Spatial-temporal changes of Cd in Jiaozhou Bay [J]. Computer Life, 2016, 4(5): 446-450.

7. Dongfang Yang, Fengyou Wang, Sixi Zhu, Ming Wang, Xiuqin Yang. The influence of marine current to $\mathrm{Cd}$ in Jiaozhou Bay [J]. World Scientific Research Journal, 2016, 2(1): 38-42.

8. Dongfang Yang, Sixi Zhu, Ming Wang, Xiuqin Yang, Fengyou Wang. High settling process of $\mathrm{Cd}$ in Jiaozhou Bay $[\mathrm{J}]$. International Core Journal of Engineering, 2016, 2(8): 1-4.

9. Dongfang Yang, Danfeng Yang, Sixi Zhu, Zhikang Wang and Ming Wang. Transfer process of $\mathrm{Cd}$ in the bay mouth of Jiaozhou Bay [J]. Journal of Computing and Electronic Information Management, 2016, 3(5): 467-474.

10. Dongfang Yang, Sixi Zhu, Zhikang Wang, Chunhua $\mathrm{Su}$ and Fengyou Wang. Dynamic change of Cd's sedimentation process in Jiaozhou Bay [J]. Journal of Computing and Electronic Information Management, 2017, 4(1): 1-9.

11. YANG D F, CHEN Y, GAO Z H, et al. Silicon Limitation on primary production and its destiny in Jiaozhou Bay, China IV transect offshore the coast with estuaries [J]. Chin. J. OceanoL. LimnoL. 2005, 23(1): 72-90.

12. Dongfang Yang, Fan Wang, Zhenhui Gao, et al. Ecological Phenomena of Phytoplankton in Jiaozhou Bay [J]. Marine Science, 2004, 28 (6): 71-74.

13. State Oceanic Administration. The Specification for Marine Monitoring [Z]. Beijing: China Ocean Press, 1991. 